\title{
A THRESHOLD ANALYSIS OF THE COST-EFFECTIVENESS OF ARTEMISININ-BASED COMBINATION THERAPIES IN SUB-SAHARAN AFRICA
}

\author{
PAUL G. COLEMAN, CHANTAL MOREL, SAM SHILLCUTT, CATHERINE GOODMAN, AND ANNE J. MILLS \\ Disease Control and Vector Biology Unit, Department of Infectious and Tropical Diseases, and Health Economics and Financing \\ Program, Department of Public Health and Policy, Health Policy Unit, London School of Hygiene and Tropical Medicine, London, \\ United Kingdom; Health Economics Research Centre, University of Oxford, Oxford, United Kingdom; Department of Economics, \\ City University, London, United Kingdom
}

\begin{abstract}
Artemisinin-based combination therapies (ACTs) are generally regarded as vital in addressing the growing problem posed by the development of antimalarial resistance across sub-Saharan Africa. However, the costs of the new ACTs are likely to be significantly higher than current therapies. Therefore, it is important to examine formally the cost-effectiveness of the more effective yet more expensive ACTs before advocating a switch in policy. Importantly, any such economic evaluation must consider the temporal dynamics of drug resistance, and not just focus on the static question of whether switching today would be cost-effective at current levels of resistance, particularly since the development of new antimalarials in the future is so uncertain. However, predicting the future changes in drug resistance is a major difficulty in accurately quantifying the relative costs and health outcomes associated with different drug therapies over time. Here, we use a simple decision tree model to estimate the incremental cost-effectiveness of using ACTs, compared with persisting with current therapies, over 5-, 10-, and 15-year periods. We describe the dynamics of drug resistance using a general logistic growth function, in which the starting frequency of resistance and maximum growth may be altered. However, rather than make assumptions about the absolute rate at which resistance to ACTs will progress, we allow the ratio of the growth rate of resistance to ACTs relative to that of current therapies to vary. Defining the growth rate of ACT resistance in this manner allows us to calculate the threshold ratio at which ACTs would no longer appear cost-effective, for any starting conditions of resistance to current therapies and ACTs, and over any time period. The influence of uncertainty in other decision tree parameters on the threshold ratio values is also quantified, using Monte Carlo simulation techniques. This analysis shows that ACTs are more than $95 \%$ likely to be cost-effective under most conditions, other than very low levels of initial resistance to sulfadoxine/pyrimethamine and a five-year time frame. These predictions are conservative in that $95 \%$ certainty is a stringent decision rule favoring the rejection of new policies. The importance of other variables not included in the analysis for the robustness of the findings are discussed (e.g., consideration of the entire population at risk for malaria, the affordability of ACTs in specific settings, and the growth of resistance modeled according to population genetic parameters).
\end{abstract}

\section{INTRODUCTION}

In sub-Saharan Africa, the growth of resistance to the widely used and affordable antimalarial drugs such as chloroquine and sulfadoxine-pyrimethamine $(\mathrm{SP})$ is recognized as a growing problem. ${ }^{1,2}$ Artemisinin-based combination therapies (ACTs) are generally regarded as a vital component in addressing the crisis, ${ }^{3}$ with a range of ACTs shown to be highly effective in treating malaria in areas with high levels of first-line drug resistance. ${ }^{4}$ Moreover, theoretical arguments suggest that the use of antimalarial therapies in combination with artemisinin-derivatives will slow the rate at which resistance emerges. ${ }^{5,6}$

However, the costs of the new ACTs are likely to be an order of magnitude more expensive than current therapies. ${ }^{7,8}$ Therefore, it is important to examine formally the costeffectiveness of the potentially more effective yet more expensive ACTs before advocating a switch in policy. Importantly, any such cost-effectiveness analysis must consider the temporal dynamics of drug resistance and not just focus on the static question of whether switching today would be costeffective at current levels of resistance; as drug resistance emerges and spreads, the cost-effectiveness ratio changes depending on what time frame of analysis is chosen. ${ }^{9}$ These temporal considerations are particularly important in the case of ACTs, since the potential consequences are grave of having widespread resistance to artemisinin and its derivatives at some point in the future, without any alternative therapies.

However, predicting the future trajectory of drug resistance is extremely difficult, particularly for ACTs, which have yet to be widely used as first-line therapy in sub-Saharan Africa. As a result, basic knowledge about drug usage patterns, and the time to emergence and the rate of spread of resistance, are not yet available. In the absence of such basic parameters, we propose a theoretical approach to help understand the threshold conditions under which the introduction of ACTs is likely to be cost-effective relative to the strategy of retaining a monotherapy as first-line treatment. The analysis uses a simple decision tree framework that allows the disease burden and costs associated with a first-line antimalarial treatment to be estimated, while explicitly taking into account the growth of resistance to treatments through time. The threshold conditions under which ACTs are cost-effective relative to retaining a monotherapy are described as a function of two main variables: 1) the growth rate of resistance of the ACT therapy relative to the monotherapy, and 2) the starting level of resistance of the monotherapy. While the model is generic, in that it can be used to examine a range of alternative firstline scenarios, we restrict our detailed analysis to comparing the cost-effectiveness of artemisinin-based combination drugs relative to a baseline scenario of retaining SP over a set period of time. The importance of the results and the usefulness of the novel quantitative approach are discussed.

\section{METHODS}

A simple decision tree, based on a previous model used to evaluate the optimal time to switch first line antimalarial therapies, ${ }^{9}$ was developed to quantify the cost-effectiveness of using an ACT rather than an existing therapy over a fixed number of years, $N$. The decision tree, shown in Figure 1, 


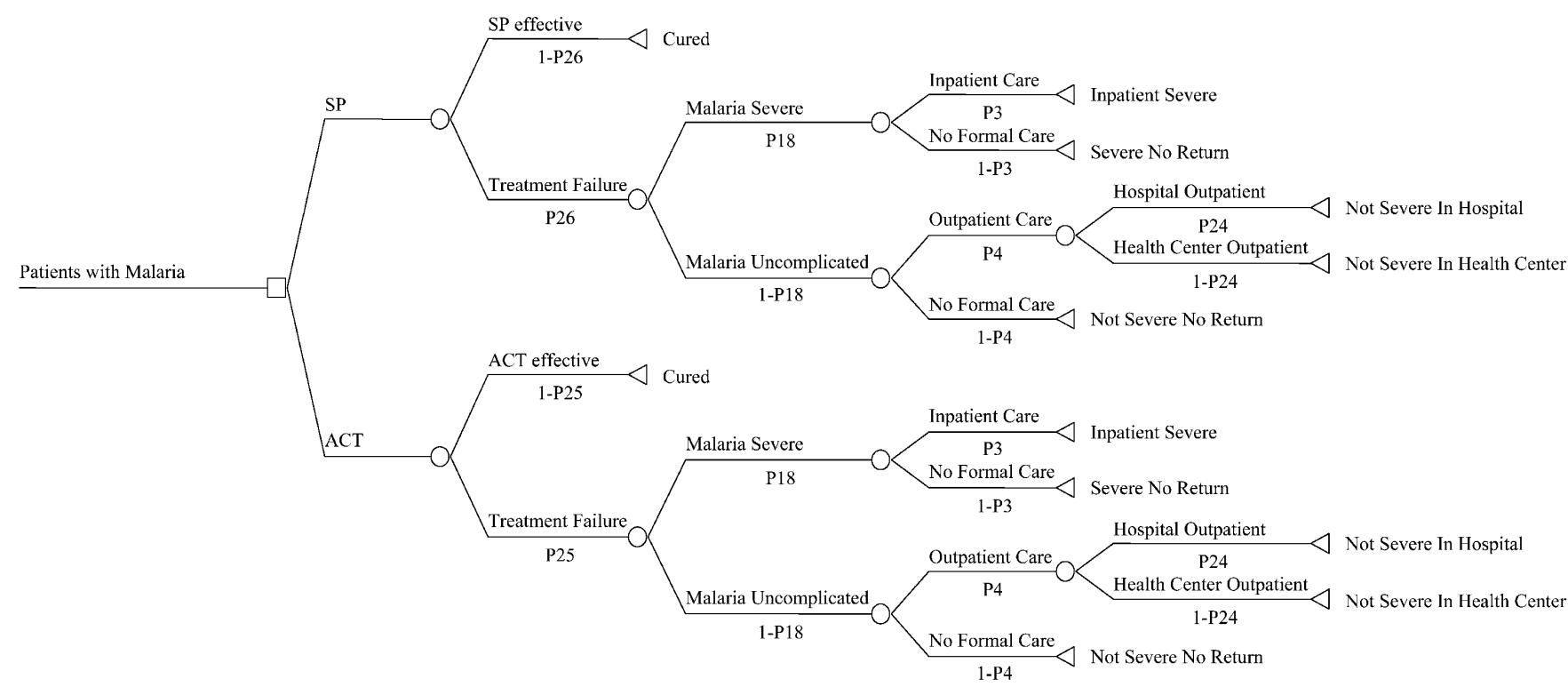

FIGURE 1. Summary of the decision tree used to compare the cost-effectiveness of artemisinin-based combination therapies (ACTs) versus monotherapy (in this case sulfadoxine-pyrimethamine [SP]). All probabilities are defined in Table 1.

follows the possible outcome of a patient presenting with malaria and receiving first-line treatment. In the first instance, the patient may be either cured or experience treatment failure. Cure was defined as adequate clinical response following criteria of the World Health Organization. ${ }^{10}$ The average health consequences (expressed as disability adjusted life years [DALYs]) and costs (US\$2002) per patient associated with a given first-line drug regimen, may then be calculated by following the decision tree paths to the end points as shown in Figure 1 and Table 1 . The decision is considered from a provider's perspective, and is restricted to those true malaria cases presenting at formal outpatient facilities, with the outpatient population weighted by the proportions $<5$ years old and $\geq 5$ years old (Table 1 ). ${ }^{11}$

Treatment failure. The probability of treatment failure, $F$, (P25 and P26 in Figure 1 and Table 1) with a given first line drug, $i$, at time $t$ was defined as being dependent on three main inputs: first, the proportion of malaria parasites, $R$, resistant to drug $i$ at time $t$; second, the probability, $m$, that a patient complies at the recommended dose with drug therapy $i$; and third, the probability, $p$, that therapy $i$ is effective despite the patient failing to comply fully with the treatment regimen.

We assumed that any patient infected with resistant parasites experiences treatment failure, regardless of whether they fully comply with the treatment regimen. As such, there are only two possible ways in which treatment with drug $i$ at time $t$ may be successful. First, the patient is not infected with resistant parasites and fully complies with the treatment regimen; the probability of this occurring is $\left(1-R_{i, t}\right) m_{i}$. Alternatively, the patient may be infected with susceptible parasites but, despite not complying with the treatment regimen, is still cured; the probability of this occurring is $\left(1-R_{i, t}\right)\left(1-m_{i}\right) p_{i}$. The overall probability of treatment success is the sum of these two probabilities, while treatment failure is simply one minus treatment success. Thus

$$
F_{i, t}=1-\left[\left(1-R_{i, t}\right) m_{i}+\left(1-R_{i, t}\right)\left(1-m_{i}\right) p_{i}\right]
$$

defines treatment failure, which simplifies to

$$
F_{i, t}=1-\left(1-R_{i, t}\right)\left[m_{i}+p_{i}\left(1-m_{i}\right)\right]
$$

The dynamic spread of drug resistance through time was modeled using a logistic growth function of the form

$$
R_{i, t}=k_{i}\left[\frac{R_{i, 0}}{R_{i, 0}+\left(k_{i}-R_{i, 0}\right) \exp ^{-r_{i} t}}\right]
$$

where $R_{i, 0}$ is the level of drug resistance to treatment $i$ at the start of the $N$-year time period; $k_{i}$ is the maximum possible level of drug resistance, which cannot exceed 1 (i.e., at $k_{i}=1$ the entire malarial parasite population would be resistant to drug $i$ ); and $r_{i}$ is the maximum growth rate of resistance against drug $i$, which occurs when $R_{i, 0}$ approaches zero.

We assume $m_{i}$ and $p_{i}$ remain constant with time over the $N$-year period of evaluation, although in practice patient compliance is likely to be influenced by the effectiveness of the drug (and in turn, the rate of development of resistance will also be dependent on patient usage patterns). The dynamics of treatment failure, as described by equation 2 , are driven by the growth of resistance given by equation 3 . To illustrate this, Figure 2 shows the temporal changes in treatment failure for two alternative drug regimens used over a 10-year period as predicted by equations 2 and 3 .

DALYs and costs. The decision tree allows the average costs, $c$, associated with first-line treatment failure, $c_{i, F}$, and success, $c_{i, S}$, to be calculated (Figure 1 and Table 1 ). Similarly, the average DALY burden associated with treatment failure, $e_{i, F}$, and success, $e_{i, S}$, may also be estimated. The total costs, $C$, over the full $N$-year period associated with using drug $i$ as the first line treatment, were then calculated as

$$
C_{i}=\int_{t=0}^{t=N}\left[F_{i, t} c_{i, F}+\left(1-F_{i, t}\right) c_{i, S}\right](1-\delta)^{t} \mathrm{~d} t
$$

and the total DALY burden, $E$, incurred over the same period was estimated as 
TABLE 1

Parameter values used in the model with the variables grouped into three categories: (a) effectiveness inputs, (b) cost inputs, and (c) probability inputs*

\begin{tabular}{|c|c|c|c|c|c|c|c|c|}
\hline & (a) Effectiveness input & $\begin{array}{l}\text { Type of probability } \\
\text { distribution }\end{array}$ & $\begin{array}{c}\text { Best } \\
\text { estimate }\end{array}$ & $\begin{array}{l}\text { Low } \\
\text { estimate }\end{array}$ & $\begin{array}{c}\text { High } \\
\text { estimate }\end{array}$ & Mean & SD & $\begin{array}{c}\text { Source } \\
\text { (reference) }\end{array}$ \\
\hline \multicolumn{9}{|c|}{ Disability weights } \\
\hline E1 & Illness not severe & Point estimate & 0.21 & & & & & 12 \\
\hline E2 & Immediate, successful treatment of malaria & Point estimate & 0.21 & & & & & 12 \\
\hline E3 & Inpatient & Point estimate & 0.25 & & & & & 12 \\
\hline & Neurologic sequelae & Point estimate & 0.47 & & & & & 12 \\
\hline \multicolumn{9}{|c|}{ Duration of illness } \\
\hline E5 & Illness not severe (years) & Point estimate & 0.02 & \multirow{4}{*}{2} & \multirow{4}{*}{10} & \multirow{4}{*}{5.387} & \multirow{4}{*}{1.411} & Estimate \\
\hline E6 & Immediate treatment (years) & Point estimate & 0.01 & & & & & Estimate \\
\hline E7 & Inpatient (days) & Lognormal & 4.5 & & & & & 13 \\
\hline & Neurologic sequelae (years) & Point estimate & 35.4 & & & & & 12 \\
\hline \multicolumn{9}{|c|}{ Disability adjusted years of life lost due to premature death } \\
\hline E9 & Average age of death $\geq 5$ years; 27 years & Point estimate & 24.83 & \multirow{2}{*}{\multicolumn{5}{|c|}{$\begin{array}{l}\text { Calculated using standard DALY methodology (see Methods) } \\
\text { Calculated using standard DALY methodology (see Methods) }\end{array}$}} \\
\hline E10 & Average age of death $<5$ years; 2 years & Point estimate & 27.47 & & & & & \\
\hline \multicolumn{9}{|c|}{ Calculation of burden } \\
\hline E11 & Cured & & & $\mathrm{E} 1 \times \mathrm{E} 5$ & & & & \\
\hline E12 & Not severely ill and not return for treatment & & & E13 & & & & \\
\hline E13 & Not severely ill and return for treatment & & & $\mathrm{E} 5 / 365 \times$ & & & & \\
\hline E14 & Severely ill at home & & & E15 & & & & \\
\hline E15 & Severely ill in the hospital & & & $\mathrm{E} 7 \times \mathrm{E} 3 / 3$ & & & & \\
\hline E16 & \multicolumn{3}{|l|}{$\begin{array}{l}\text { Severely ill in inpatient care (including hospital, } \\
\text { death, neurologic sequelae) (age } \geq 5 \text { ) }\end{array}$} & \multicolumn{5}{|c|}{$\mathrm{E} 15+(\mathrm{P} 8 \times \mathrm{E} 9)+(\mathrm{P} 9 \times \mathrm{E} 8 \times \mathrm{E} 4)$} \\
\hline & \multicolumn{3}{|l|}{$\begin{array}{l}\text { Severely ill in inpatient care (incl: hospital, death, } \\
\text { neurological sequelae) (age }<5 \text { ) }\end{array}$} & \\
\hline \multirow{5}{*}{$\begin{array}{l}\text { E18 } \\
\text { E19 } \\
\text { E20 } \\
\text { E21 }\end{array}$} & Severely ill in inpatient care (age-weighted) & & & \multirow{4}{*}{\multicolumn{5}{|c|}{$\begin{array}{l}(\mathrm{P} 7 \times \mathrm{E} 16)+(\mathrm{P} 13 \times \mathrm{E} 17) \\
\mathrm{E} 14+(\mathrm{P} 11 \times \mathrm{E} 9)+(\mathrm{P} 9 \times \mathrm{E} 8 \times \mathrm{E} 4) \\
\mathrm{E} 14+(\mathrm{P} 17 \times \mathrm{E} 10)+(\mathrm{P} 15 \times \mathrm{E} 8 \times \mathrm{E} 4) \\
(\mathrm{P} 7 \times \mathrm{E} 19)+(\mathrm{P} 13 \times \mathrm{E} 20)\end{array}$}} \\
\hline & Severely ill without inpatient care (age $\geq 5)$ & & & & & & & \\
\hline & Severely ill without inpatient care $(<5)$ & & & & & & & \\
\hline & Severely ill without inpatient care (age-weigh & ted) & & & & & & \\
\hline & (b) Cost input & $\begin{array}{l}\text { Type of probability } \\
\text { distribution }\end{array}$ & $\begin{array}{c}\text { Best } \\
\text { estimate }\end{array}$ & $\begin{array}{c}\text { Low } \\
\text { estimate }\end{array}$ & $\begin{array}{c}\text { High } \\
\text { estimate }\end{array}$ & Mean & SD & $\begin{array}{c}\text { Source } \\
\text { (reference) }\end{array}$ \\
\hline \multicolumn{9}{|c|}{ Drug costs } \\
\hline & $\mathrm{ACT}$ & Lognormal & 2.4 & 1.2 & 3.9 & 2.513 & 1.276 & $\begin{array}{r}21 \\
8\end{array}$ \\
\hline $\mathrm{C} 2$ & Quinine (2nd line for inpatients) & Point estimate & 2.59 & & & & & 13 \\
\hline $\mathrm{C} 3$ & SP (1st line comparator) & Point estimate & 0.12 & & & & & 8 \\
\hline $\mathrm{C} 4$ & Amodiaquine (2nd line for outpatients) & Point estimate & 0.14 & & & & & 8 \\
\hline \multicolumn{9}{|c|}{ Medical costs } \\
\hline C5 & $\begin{array}{l}\text { Cost to patient of attending an outpatient } \\
\text { facility (excluding fees) }\end{array}$ & Lognormal & 0.74 & 0.18 & 1.68 & 0.871 & 1.505 & 13 \\
\hline C6 & Hospital outpatient facility costs per visit & Lognormal & 3.9 & 0.91 & 6.08 & 3.832 & 1.376 & 13 \\
\hline & $\begin{array}{l}\text { Health center outpatient facility costs } \\
\text { per visit }\end{array}$ & Lognormal & 0.72 & 0.34 & 1.35 & 0.798 & 1335 & 13 \\
\hline & Cost to patient of attending inpatient facility & & & & & & & \\
\hline & (excluding fees) & Lognormal & 3.84 & 1.11 & 9.37 & 4.724 & 1.514 & 13 \\
\hline C9 & Cost of inpatient facility per day & Lognormal & 14.15 & 4.57 & 24.48 & 14.750 & 1.368 & 13 \\
\hline Formu & las for derived variables & & & & & & & \\
\hline $\mathrm{C} 10$ & Weighted cost of ACT & & & $\mathrm{P} 7 \times \mathrm{C} 1 \times$ & $\times \mathrm{P} 12 \times$ & & & \\
\hline $\mathrm{C} 11$ & Total health center outpatient care costs, & & & $\mathrm{C} 7 \times(1-\mathrm{P}$ & $x(1-P 22)$ & & & \\
\hline $\mathrm{C} 12$ & Total hospital outpatient care costs, excluding & & & & & & & \\
\hline & fixed and drug costs & & & $\mathrm{C} 6 \times(1-\mathrm{P}$ & $\times(1-\mathrm{P} 22$ & & & \\
\hline $\mathrm{C} 13$ & Total cost of inpatient care & & & $\mathrm{E} 7 \times \mathrm{C} 14$ & & & & \\
\hline $\mathrm{C} 14$ & Cost of inpatient facility per day, subtracting & & & & & & & \\
\hline & fixed and drug costs & & & $\mathrm{C} 9 \times(1-\mathrm{P}$ & $\times(1-\mathrm{P} 20)$ & & & \\
\hline
\end{tabular}

$$
E_{i}=\int_{t=0}^{t=N}\left[F_{i, t} e_{i, F}+\left(1-F_{i, t}\right) e_{i, S}\right](1-\delta)^{t} \mathrm{~d} t
$$

where $\delta$ is the annual discount rate. The incremental cost effectiveness ratio (ICER) of using an ACT relative to the existing drug, $X$, over the full $N$-year period was given as

$$
\mathrm{ICER}=\frac{C_{A C T}-C_{X}}{E_{X}-E_{A C T}} .
$$

The DALYs were calculated using standard methods, ${ }^{12}$ assuming age-specific life expectancies based on a United Na- tions west African life table with average life expectancy of 50 years at birth and a $3 \%$ discount rate. The costing methodology followed that described by Goodman and others, ${ }^{11,13}$ and used the ingredients approach, with all prices converted to 2002 US dollars.

Drug regimen comparison and parameter values. The model was anchored to the real world by using the framework to compare the use of either SP or an ACT as a first-line therapy in a high transmission setting of a low-income, subSaharan African country (as defined by Goodman and others ${ }^{11}$ ). A baseline time period of $N=10$ years (varied to a 
TABLE 1

Continued

\begin{tabular}{|c|c|c|c|c|c|c|c|}
\hline (c) Probability input & $\begin{array}{l}\text { Type of probability } \\
\text { distribution }\end{array}$ & $\begin{array}{c}\text { Best } \\
\text { estimate }\end{array}$ & $\begin{array}{l}\text { Low } \\
\text { estimate }\end{array}$ & $\begin{array}{c}\text { High } \\
\text { estimate }\end{array}$ & $\alpha$ & $\beta$ & $\begin{array}{c}\text { Source } \\
\text { (reference) }\end{array}$ \\
\hline \multicolumn{8}{|l|}{ Compliance } \\
\hline P1 Compliance to ACT & Uniform & & 0.3 & 0.6 & & & 13 \\
\hline P2 Compliance to SP & Uniform & & 0.85 & 0.95 & & & 13 \\
\hline $\begin{array}{l}\text { P3 Patient with severe malaria returns to } \\
\text { clinic after treatment failure }\end{array}$ & Beta & 0.48 & 0.19 & 0.88 & 5.630 & 5.470 & 13 \\
\hline $\begin{array}{l}\text { P4 Patient with uncomplicated malaria } \\
\text { returns to clinic after treatment failure }\end{array}$ & Beta & 0.48 & 0.19 & 0.88 & 5.630 & 5.470 & 13 \\
\hline $\begin{array}{l}\text { P5 Probability that ACT is effective if patient } \\
\text { is not fully compliant }\end{array}$ & Beta & 0.2 & 0.1 & 0.3 & 16.945 & 66.357 & Estimate \\
\hline $\begin{array}{l}\text { P6 Probability that SP is effective if patient } \\
\text { is not fully compliant }\end{array}$ & Point estimate & 0 & & & & & 13 \\
\hline \multicolumn{8}{|l|}{ Over-five population } \\
\hline P7 Proportion of population (age $\geq 5$ ) & & 0.5 & & & & & Estimate \\
\hline $\begin{array}{l}\text { P8 Patient with severe malaria attending an } \\
\text { inpatient facility dies }(\text { age } \geq 5)\end{array}$ & Beta & 0.1 & 0.075 & 0.125 & 74.26 & 666.607 & 13 \\
\hline $\begin{array}{l}\text { P9 Severe malaria leads to neurological } \\
\text { sequelae }(\text { age } \geq 5)\end{array}$ & Beta & 0.005 & 0.0025 & 0.0075 & 26.399 & 5021.169 & 13 \\
\hline $\begin{array}{l}\text { P10 Treatment failure leads to severe } \\
\text { malaria }(\text { age } \geq 5)\end{array}$ & Beta & 0.01 & 0.005 & 0.015 & 20.885 & 2022.724 & 13 \\
\hline $\begin{array}{l}\text { P11 Probability that a patient that does not } \\
\text { return for formal care will die }(\text { age } \geq 5)\end{array}$ & Beta & 0.25 & 0.2 & 0.3 & 110.007 & 329.014 & 13 \\
\hline \multicolumn{8}{|l|}{ Under-five population } \\
\hline P12 Proportion of full dose received $($ age $<5)$ & Point estimate & 0.5 & & & & & Estimate \\
\hline P13 Proportion of the population $($ age $<5)$ & Point estimate & 0.5 & & & & & Estimate \\
\hline $\begin{array}{l}\text { P14 Patient with severe malaria attending an } \\
\text { inpatient facility dies }(\text { age }<5)\end{array}$ & Beta & 0.192 & 0.1 & 0.3 & 16.374 & 65.706 & 13 \\
\hline $\begin{array}{l}\text { P15 Severe malaria leads to neurologic } \\
\text { sequelae }(\text { age }<5)\end{array}$ & Beta & 0.0132 & 0.0041 & 0.0224 & 10.820 & 773.322 & 13 \\
\hline $\begin{array}{l}\text { P16 Treatment failure leads to severe } \\
\text { malaria }(\text { age }<5)\end{array}$ & Beta & 0.05 & 0.03 & 0.07 & 31.302 & 586.235 & 13 \\
\hline $\begin{array}{l}\text { P17 Probability that a patient that does not } \\
\text { return for formal care will die }(\text { age }<5)\end{array}$ & Beta & 0.5 & 0.4 & 0.6 & 65.644 & 65.644 & 13 \\
\hline \multicolumn{8}{|l|}{ Age-weighted probability } \\
\hline $\begin{array}{l}\text { P18 Treatment failure leads to severe } \\
\text { malaria (age-weighted) }\end{array}$ & & \multicolumn{6}{|c|}{$(\mathrm{P} 7 \times \mathrm{P} 10)+(\mathrm{P} 13 \times \mathrm{P} 16)$} \\
\hline \multicolumn{8}{|l|}{ Inpatient probabilities } \\
\hline P19 Proportion of inpatient costs that are drugs & Point estimate & 0.17 & & & & & 13 \\
\hline $\begin{array}{l}\text { P20 Proportion of inpatient facility costs that } \\
\text { are fixed }\end{array}$ & Uniform & & 0.5 & 0.75 & & & 13 \\
\hline \multicolumn{8}{|l|}{ Outpatient probabilities } \\
\hline P21 Proportion of outpatient costs that are drugs & Point estimate & 0.37 & & & & & 13 \\
\hline $\begin{array}{l}\text { P22 Proportion of outpatient facility costs } \\
\text { that are fixed }\end{array}$ & Uniform & & 0.25 & 0.4 & & & 13 \\
\hline P23 Outpatient visit takes place at a health center & Point estimate & 0.68 & & & & & 13 \\
\hline P24 Outpatient visit takes place at a hospital & Point estimate & 0.32 & & & & & 13 \\
\hline \multicolumn{8}{|l|}{ Resistance probabilities and other variables } \\
\hline \multicolumn{8}{|l|}{$\mathrm{ACT}$} \\
\hline $\mathrm{R}_{\mathrm{ACT}, 0}$ Initial parasite resistance to ACT & $\begin{array}{l}\text { Tested at two } \\
\text { levels }\end{array}$ & & 0.001 & 0.01 & & & Estimate \\
\hline $\mathrm{r}_{\mathrm{ACT}}$ Growth rate of resistance to ACT & & \multicolumn{6}{|c|}{$\mathrm{r}_{\mathrm{ACT}} / \mathrm{r}_{\mathrm{SP}} \times \mathrm{r}_{\mathrm{SP}}$} \\
\hline $\begin{array}{l}\mathrm{k}_{\mathrm{ACT}} \text { Maximum level of resistance to ACT } \\
\mathrm{R}_{\mathrm{ACT}, \mathrm{t}} \begin{array}{l}\text { Actual resistance to ACT at } \\
\text { different time periods }\end{array}\end{array}$ & & \multicolumn{6}{|c|}{$\mathrm{k}_{\mathrm{ACT}} \times\left(\mathrm{R}_{\mathrm{ACT}, 0} /\left(\mathrm{R}_{\mathrm{ACT}, 0}+\left(\mathrm{k}_{\mathrm{ACT}}-\mathrm{R}_{\mathrm{ACT}, 0}\right)\right)\right) \times \exp \left(-\mathrm{r}_{\mathrm{ACT}} \times \mathrm{t}\right)$} \\
\hline $\begin{array}{l}\text { P25 Probability that ACT treatment will fail } \\
\text { SP }\end{array}$ & & \multicolumn{6}{|c|}{$1-\left(1-\mathrm{R}_{\mathrm{ACT}, \mathrm{t}}\right) \times(\mathrm{P} 1+(\mathrm{P} 5 \times(1-\mathrm{P} 1)))$} \\
\hline $\mathrm{R}_{\mathrm{SP}, 0}$ Initial parasite resistance to $\mathrm{SP}$ & $\begin{array}{l}\text { Varied nine } \\
\text { times }\end{array}$ & & 0.1 & 0.9 & & & Estimates \\
\hline $\mathrm{r}_{\mathrm{SP}}$ Growth rate of resistance to SP & Beta & 0.406214 & 0.313191 & 0.513395 & 52.080 & 74.893 & 14 \\
\hline $\begin{array}{l}\mathrm{k}_{\mathrm{SP}} \text { Maximum level of resistance to } \mathrm{SP} \\
\mathrm{R}_{\mathrm{SP}, \mathrm{t}} \quad \begin{array}{c}\text { Actual resistance to SP at different } \\
\text { time periods }\end{array}\end{array}$ & & ${ }^{1} \mathrm{k}_{\mathrm{SP}} \times(\mathrm{R}$ & ${ }_{, 0} /\left(\mathrm{R}_{\mathrm{SP}, 0}+(\right.$ & $\left.\mathrm{S}_{\mathrm{SP}}-\mathrm{R}_{\mathrm{SP}, 0}\right)$ & )$\times \exp (-r$ & $s P \times t)$ & \\
\hline P26 Probability that SP treatment will fail & & $1-(1-$ & $\mathrm{P}, \mathrm{t}) \times(\mathrm{P} 2+$ & $(\mathrm{P} 6 \times(1-\mathrm{I})$ & 2))) & & \\
\hline $\begin{array}{ll}\mathrm{r}_{\mathrm{ACT}} \mathrm{r}_{\mathrm{SP}} & \begin{array}{l}\text { Relative growth rate of resistance } \\
\text { (ACT relative to SP) }\end{array}\end{array}$ & $\begin{array}{l}\text { Varied } 16 \\
\text { times }\end{array}$ & & 0.05 & 0.5 & & & Estimate \\
\hline $\mathrm{N}$ Time frame & Three scenarios & 10 & 5 & 15 & & & \\
\hline$\delta$ Annual discount rate & $\begin{array}{l}\text { Tested at } \\
\text { two levels }\end{array}$ & & $0 \%$ & $3 \%$ & & & \\
\hline
\end{tabular}




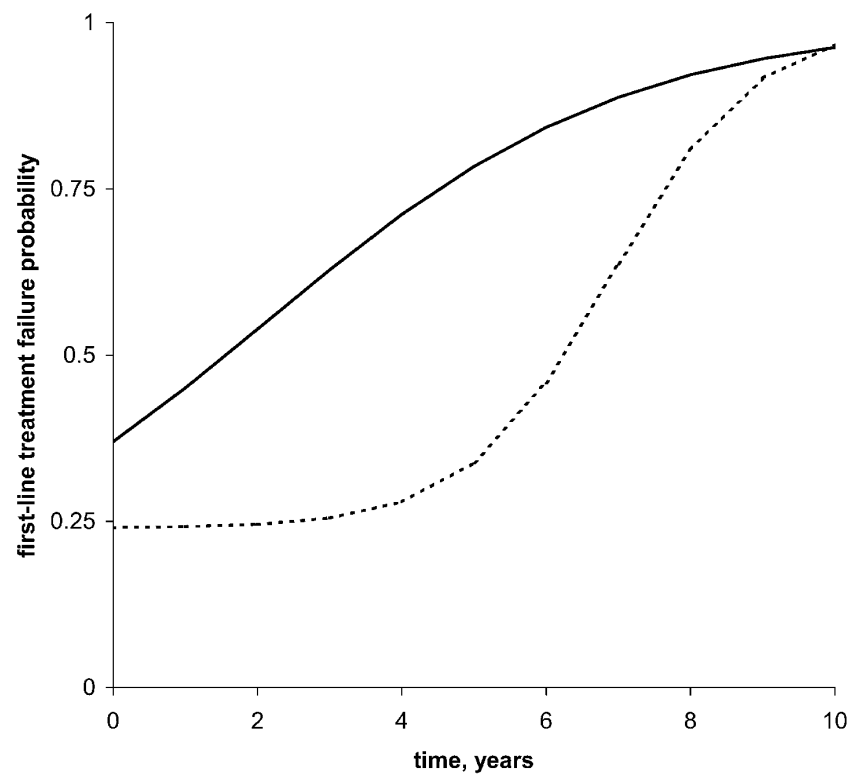

FIGURE 2. Example of the temporal dynamics of first-line treatment failure probabilities, as described by equation 2 , using the existing therapy (sulfadoxine-pyrimethamine [SP], solid line) and the artemisinin-based combination therapy (ACT, dotted line) over a 10 -year period. The ratio of $r_{A C T} / r_{S P}$ is 2.5 . (The parameter values for SP are $R_{S P, 0}=0.3, r_{S P}=0.4, k_{S P}=1, m_{S P}=0.9$, and $p_{S P}=0$. The parameter values for ACT are $R_{A C T, O}=0.001, r_{A C T}=1, k_{A C T}=1$, $m_{A C T}=0.7$, and $p_{A C T}=0.2$.)

minimum of 5 years and maximum of 15 years) and a discount rate of $3 \%$ (varied to $0 \%$ ) per year were chosen.

The maximum growth rate of SP resistance, $r_{S P}$, was estimated from longitudinal drug resistance studies conducted in eastern and southern Africa. ${ }^{14}$ The maximum growth rate of ACT, $r_{A C T}$, was defined relative to $r_{S P}$, with the ratio $r_{A C T} / r_{S P}$ varied from 0.05 upwards. The baseline starting condition for ACT resistance at $t=0$ was set at 0.001 (i.e., one parasite per 1,000 would show resistance to the ACT), and was also varied to a maximum of 0.01 (i.e., one parasite per 100 showing resistance).

All input parameter values and their sources are shown in Table 1. Scarcity of data restricted parameter definitions to best estimates and likely ranges, represented by triangular distributions. ${ }^{9}$ However, to redistribute probability density to its most likely form, standard distributions were fitted to the triangles by minimizing the square of the distance between the two distributions. Standard beta distributions, bounded by 0 and 1 , were appropriate for parameters representing probabilities. Lognormal distributions, bounded by 0 with a positive skew, were appropriate for parameters representing costs, since there is a marginal likelihood that variable costs may be disproportionately high. Point estimates were used for parameters for which uncertainty was not reported or unknown, such as disability weights, or parameters that were known with absolute certainty.

A continuous, linear cost function with zero fixed costs was assumed. Consequently, a child's dose, assumed to be $50 \%$ of an adult dose, cost $50 \%$ of the adult dose. The range for the cost of ACT was made from estimates for artesunate/SP (low estimate), Co-Artem ${ }^{\circledR}$ (Novartis International AG, Basel, Switzerland) artemether-lumefantrine (best estimate), and artesunate/mefloquine (high estimate).
The model does not take into account policy change costs. In practice, a range of costs, such as improved diagnostics and regulatory measures, may accompany a change in treatment regimes (e.g., to a more advanced drug such as ACT). The magnitude of these costs is currently unknown.

Monte Carlo simulation and threshold estimation. For combinations of SP starting resistance and values of $r_{A C T} / r_{S P}$, the model was iterated 3,000 times. At each iteration, input parameter values were chosen at random from the probability distributions defined in Table 1, and the ICER of using an ACT relative to SP over the $N$-year time period calculated according to equation 6 . The calculated ICER was compared with a cut-off value of \$150/DALY averted, a rough economic evaluation criterion by which a health intervention in a developing country may be judged to be "attractive". ${ }^{15}$ For any starting condition of SP resistance, the threshold value of the ratio $r_{A C T} / r_{S P}$ at which $95 \%$ of the model iterations were cost-effective at the \$150/DALY level was then recorded. A cost-effectiveness probability surface was drawn to show the threshold conditions under which the use of the ACT over the $N$-year period would be considered cost-effective with $95 \%$ certainty at the $\$ 150 /$ DALY level.

Standard acceptability curves were constructed to represent uncertainty around the \$150/DALY averted decision rule, and to make cost-effectiveness results comparable to opportunity costs represented by other medical interventions. To make this analysis possible, we chose scenarios with starting levels of resistance to SP at $10 \%, 30 \%$, and $50 \%$, and with resistance growing at an equal trajectory for both drugs $\left(r_{A C T} / r_{S P}=1\right)$. To quantify the levels of cost-effectiveness given in these figures, and to allow for considerations of affordability, per-person incremental costs, incremental DALYs averted, and cost-effectiveness ratios were recorded.

The model iterations were conducted in Microsoft (Redmond, WA) Excel ${ }^{\circledR}$ using the @Risk add-in tool (Palisade Corporation, Newfield, NY).

\section{RESULTS}

The model results are shown in Figure 3. For the baseline scenario with a 10 -year period of comparison, $3 \%$ annual discount rate, and starting ACT resistance frequency of 0.001 , the threshold values of the ratio $r_{A C T} / r_{S P}$ vary from approximately 1.5 (at a $10 \%$ starting level of SP resistance) to 5 (at a $60 \%$ starting level of SP resistance) i.e., resistance to ACT would have to grow 1.5 times faster than resistance to SP monotherapy for acts to be the preferred policy option. Above $60 \%$ resistance to SP, ACTs are predicted to be costeffective at all considered values of $r_{A C T} / r_{S P}$.

The effects of varying the time frame to 5 and 15 years are clearly evident. Under the five-year scenario, the slope of the threshold condition is much steeper, and importantly, below an SP resistance starting condition of approximately $20 \%$, the ICER $95 \%$ confidence intervals lie above the $\$ 150 /$ DALY criterion. However, between $20 \%$ and $40 \%$, the ACT option is robustly cost-effective, with the threshold values for $r_{A C T} / r_{S P}$ lying between 3 and 5 . Above $40 \%$, ACTs are predicted to be cost-effective for all considered values of $r_{A C T} / r_{S P}$. In contrast, under the 15-year scenario, the slope of the threshold condition is shallower, with less certainty that the ACT option will be cost-effective at high levels of $r_{A C T} / r_{S P}$. 
(a)

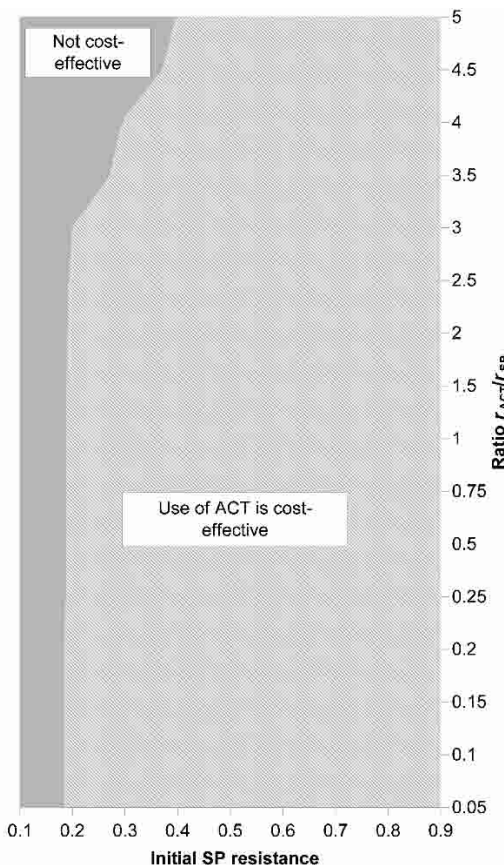

(b)

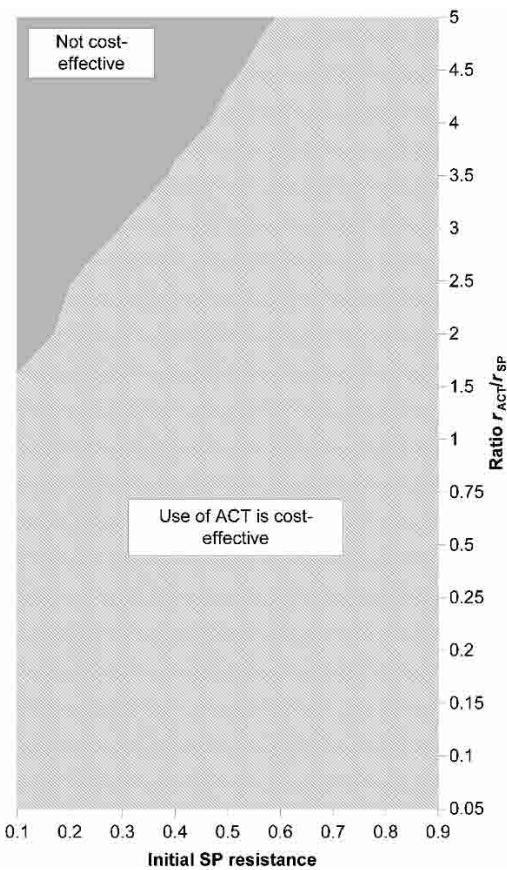

(c)

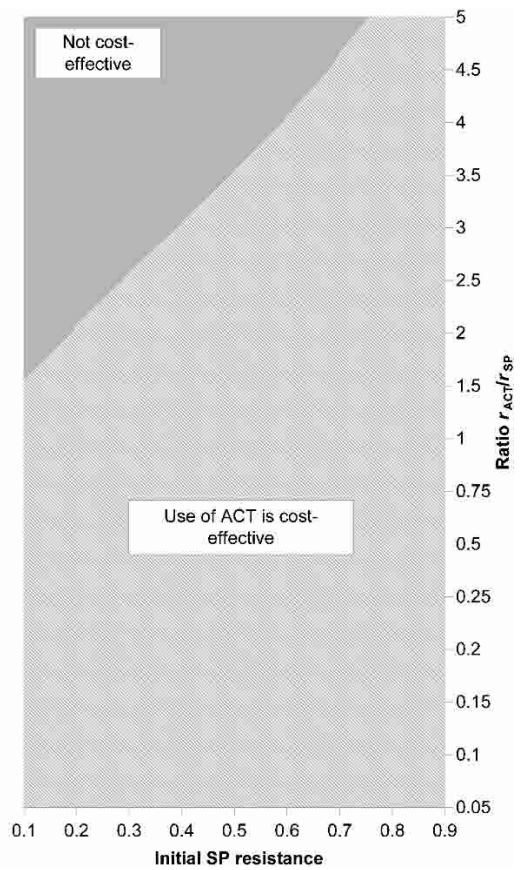

FIGURE 3. Cost-effectiveness probability plane as a function of the initial sulfadoxine-pyrimethamine (SP) level of resistance and the ratio of growth rate of artemisinin-based combination therapy (ACT) resistance relative to the growth rate of SP $\left(r_{A C T} / r_{S P}\right)$. The lighter area represents $95 \%$ of model iterations returning an incremental cost effectiveness ratio (ICER) $<\$ 150 /$ disability adjusted life years (DALYs) averted. The darker area represents the probability that the ICER is $<\$ 150 /$ DALYs averted is less than $95 \%$. The border of the lighter and darker areas represents the critical rate at which ACT resistance must develop, relative to SP, to be $95 \%$ certain that the introduction of the ACT will be cost-effective. The results were obtained using the variables described in Table 1 and assuming an ACT starting resistance of 0.001 , an annual discount rate of $3 \%$, and a time frame of (a) five years, (b) 10 years, and (c) 15 years.

Figure 4 shows the impact of increasing the starting condition of ACT drug resistance by an order of magnitude from 0.001 to 0.01 . For all times frames, the critical threshold value of the $r_{A C T} / r_{S P}$ ratio was significantly lower when using the higher starting frequency of ACT resistance. The effects of varying the discount rate to zero were negligible and the results did not noticeably differ from those shown in Figures 3 and 4 . (a)

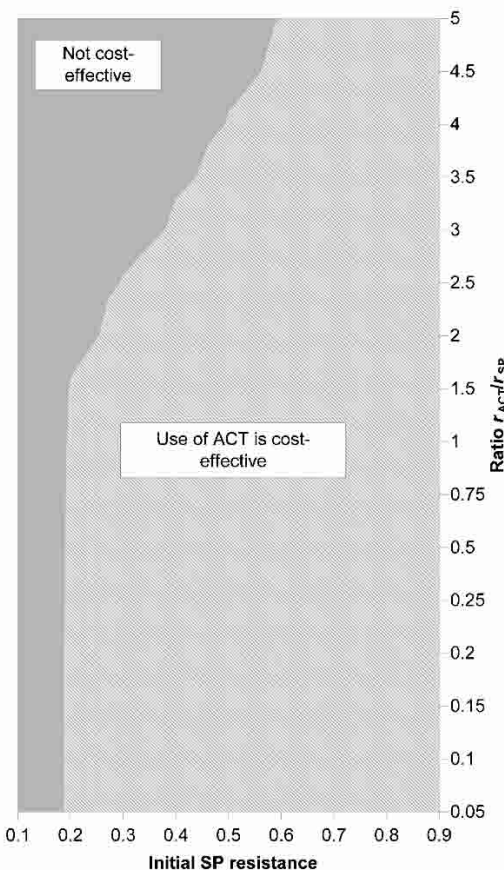

(b)

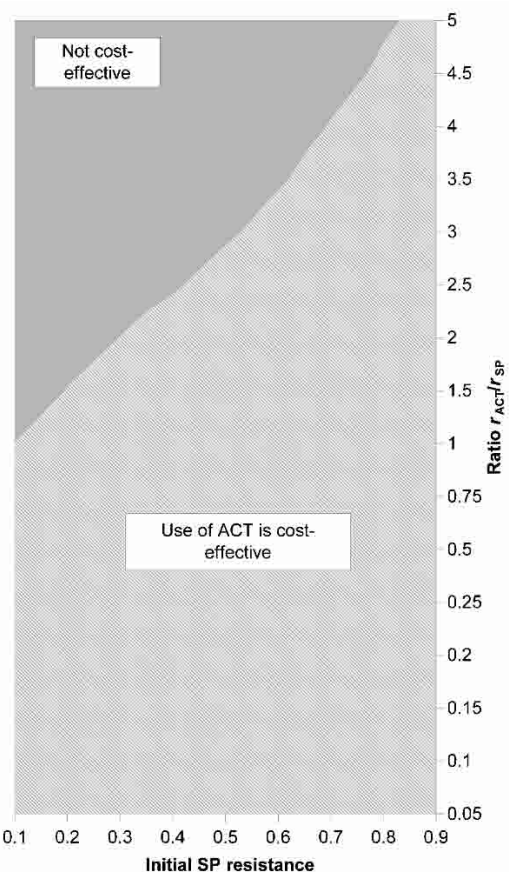

(c)

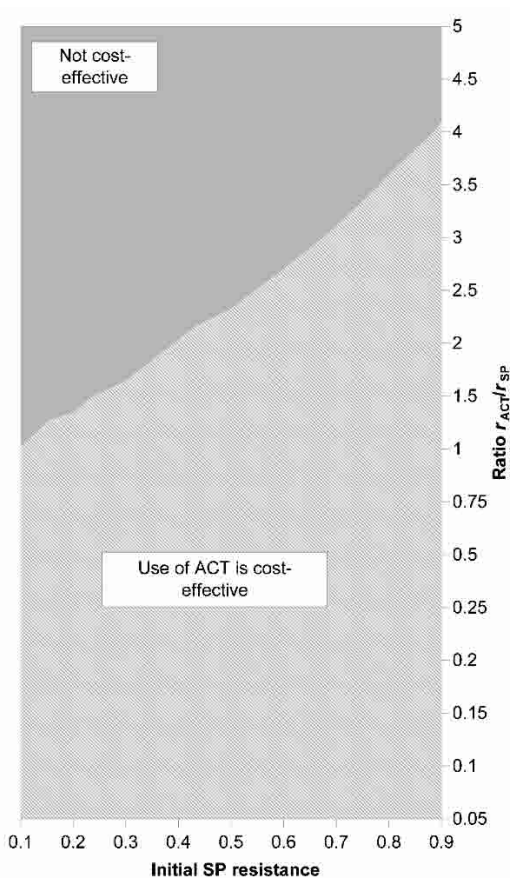

FIGURE 4. Cost-effectiveness probability plane as a function of the initial sulfadoxine-pyrimethamine (SP) level of resistance and the ratio of the growth rate of artemisinin-based combination therapy (ACT) resistance relative to the growth rate of SP $\left(r_{A C T} / r_{S P}\right)$. The parameters are as in Figure 3, but the initial frequency of ACT drug resistance is set at 0.01. (a) Five years, (b) 10 years, and (c) 15 years. 
The impact of variations in the \$150/DALY averted decision rule used to determine cost-effectiveness is shown in Figure 5. As starting levels of resistance to SP increase, costeffectiveness becomes more robust to changes in the decision

(a)

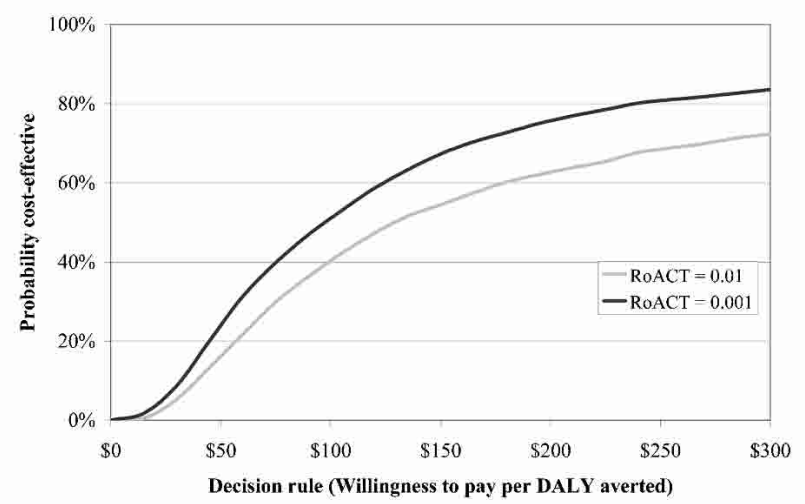

(b)

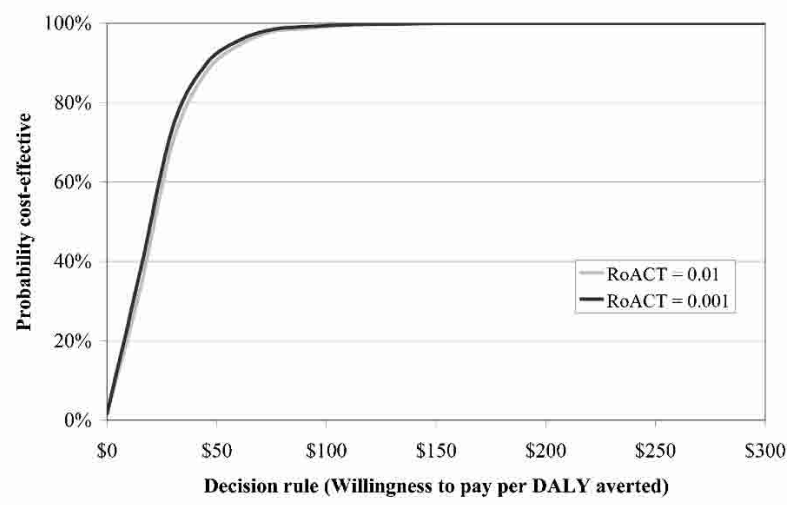

(c)

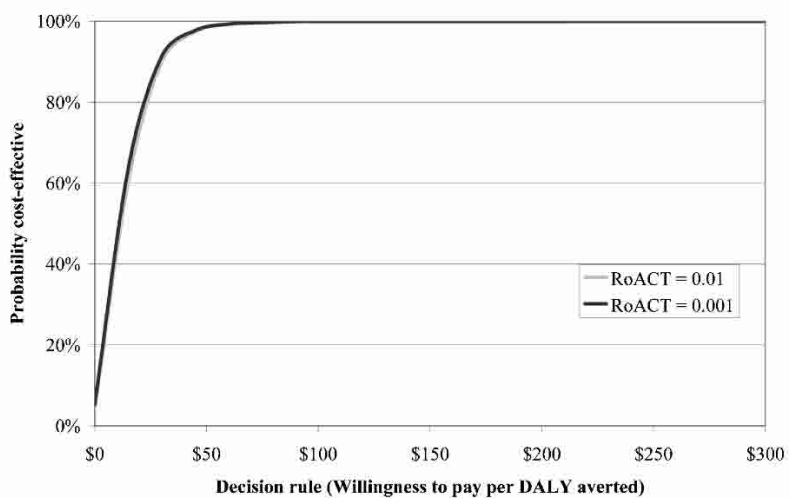

FIGURE 5. Acceptability curves showing the influence of the $\$ 150 /$ disability adjusted life years (DALYs) averted decision rule on cost-effectiveness over a five-year time period. The growth rate of artemisinin-based combination therapy (ACT) resistance relative to the growth rate of sulfadoxine-pyrimethamine (SP) $\left(r_{A C T} / r_{S P}\right)$ is assumed to equal 1 , a conservative estimate since it is unlikely that resistance will grow faster to ACT. Starting conditions for resistance to SP were considered at (a) $10 \%$, (b) $30 \%$, and (c) $50 \%$. The results were obtained using the variables described in Table 1 , assuming an ACT starting resistance of 0.01 and 0.001 , and an annual discount rate of $3 \%$. rule over a five-year time horizon. The decision rule has no impact on cost-effectiveness after 10 years or 15 years.

Tables 2 and 3 show the means of incremental per-person costs incurred, incremental DALYs averted, and ICER for each starting condition for SP-resistance and an $r_{A C T} / r_{S P}$ ratio equal to 1 . As $R_{S P, O}$ (i.e., the starting level of resistance to SP at time $\mathrm{t}=0$ ) increases, incremental costs decrease, incremental DALYs increase, and ACTs become more costeffective.

\section{DISCUSSION}

Given the dynamic nature of drug resistance, with the effects of drug policies implemented today affecting the levels of drug resistance in the future, quantitative models are required to predict the likely effects ${ }^{6,16,17}$ and costeffectiveness, ${ }^{9,18,19}$ of alternative policies aimed at ameliorating the disease burden associated with drug resistance. The analytical framework described here provides a succinct means of examining the complex and uncertain issues associated with comparing the cost-effectiveness of alternative antimalarial drug therapies. Importantly, rather than making absolute predictions of the rate at which ACT drug resistance will develop, an as yet unknown quantity, we allow the ratio of the growth rate of resistance to ACTs relative to that of current therapies to vary across a range of fixed values. Defining the growth rate of ACT resistance in this manner allows us to calculate the threshold ratio at which ACTs would no longer appear cost-effective, for any starting conditions of resistance to current therapies and ACTs, and over any time period. Also, the influences of uncertainty in other decision tree parameters on the threshold conditions are quantified using Monte Carlo simulation techniques.

The results of the simulations highlight the importance of the time frame of economic evaluation when evaluating dynamic systems. ${ }^{9}$ Taking a relatively short-term perspective (five years) shows a threshold of SP resistance below which it is not cost-effective to switch to an ACT, using the $95 \%$ decision rule. No such lower SP resistance threshold is seen with the longer 10-year and 15-year time frames. Across much of eastern and southern Africa, the level of SP drug resistance is already approximately $30 \%$ or more. ${ }^{14}$ At such levels of SP resistance, the model is consistent in its predictions, regardless of the time frame, or the assumption of initial ACT resistance levels, and the growth rate of resistance of the ACT would have to be significantly greater than that observed with SP for the ACT not to remain cost effective. Moreover, as is intuitively predictable, the higher the level of SP resistance, the more rapidly ACT drug resistance would have to spread for it not to be a cost-effective replacement strategy. At high initial levels of SP resistance, the decision to switch to ACTs is nearly certain, resistance to ACTs would have to grow extremely rapidly for them not to be cost-effective.

It should also be noted that the predicted thresholds are conservative for two reasons. First, the chosen comparator, $\mathrm{SP}$, has a higher estimated compliance (since it is taken as a single dose), and thus a lower expected failure rate for a given level of resistance, relative to other existing therapies such as amodiaquine and chloroquine. Second, the threshold condition under which the ACT strategy fails to be cost-effective was based on a stringent $95 \%$ decision rule. It has been ar- 
TABLE 2

Values for per-person incremental costs incurred, incremental DALYs averted, and ICERs as a function of the initial SP level of resistance*

\begin{tabular}{|c|c|c|c|c|c|c|c|c|c|c|c|}
\hline $\begin{array}{l}\text { (a) } \\
\mathrm{R}_{\mathrm{SP}, 0} \\
\end{array}$ & Costs incurred & DALYs averted & ICER & $\begin{array}{l}(\mathbf{b}) \\
\mathrm{R}_{\mathrm{SP}, 0}\end{array}$ & Costs incurred & DALYs averted & ICER & $\begin{array}{l}\text { (c) } \\
\mathrm{R}_{\mathrm{SP}, 0}\end{array}$ & Costs incurred & DALYs averted & ICER \\
\hline 0.1 & $\$ 5.89$ & 0.03 & $\$ 214.10$ & 0.1 & $\$ 6.19$ & 0.05 & $\$ 124.09$ & 0.1 & $\$ 6.26$ & 0.06 & $\$ 110.60$ \\
\hline 0.2 & $\$ 5.28$ & 0.10 & $\$ 53.88$ & 0.2 & $\$ 5.71$ & 0.14 & $\$ 41.32$ & 0.2 & $\$ 5.79$ & 0.15 & $\$ 39.80$ \\
\hline 0.3 & $\$ 4.93$ & 0.16 & $\$ 30.13$ & 0.3 & $\$ 5.34$ & 0.21 & $\$ 25.68$ & 0.3 & $\$ 5.41$ & 0.22 & $\$ 25.16$ \\
\hline 0.4 & $\$ 4.62$ & 0.22 & $\$ 20.97$ & 0.4 & $\$ 5.02$ & 0.27 & $\$ 18.79$ & 0.4 & $\$ 5.10$ & 0.27 & $\$ 18.56$ \\
\hline 0.5 & $\$ 4.35$ & 0.27 & $\$ 16.03$ & 0.5 & $\$ 4.74$ & 0.32 & $\$ 14.83$ & 0.5 & $\$ 4.81$ & 0.33 & $\$ 14.72$ \\
\hline 0.6 & $\$ 4.10$ & 0.32 & $\$ 12.89$ & 0.6 & $\$ 4.48$ & 0.37 & $\$ 12.21$ & 0.6 & $\$ 4.56$ & 0.37 & $\$ 12.16$ \\
\hline 0.7 & $\$ 3.87$ & 0.36 & $\$ 10.71$ & 0.7 & $\$ 4.25$ & 0.41 & $\$ 10.33$ & 0.7 & $\$ 4.32$ & 0.42 & $\$ 10.32$ \\
\hline 0.8 & $\$ 3.65$ & 0.40 & $\$ 9.09$ & 0.8 & $\$ 4.03$ & 0.45 & $\$ 8.90$ & 0.8 & $\$ 4.10$ & 0.46 & $\$ 8.92$ \\
\hline 0.9 & $\$ 3.45$ & 0.44 & $\$ 7.84$ & 0.9 & $\$ 3.82$ & 0.49 & $\$ 7.78$ & 0.9 & $\$ 3.90$ & 0.50 & $\$ 7.81$ \\
\hline
\end{tabular}

* The ratio of the growth rate of ACT resistance relative to the growth rate of SP $\left(r_{A C T} / r_{S P}\right)$ is assumed to be 1 as a conservative estimate, since it is unlikely that resistance will grow faster to ACT. The results were obtained using the variables described in Table 1 and assuming an ACT starting resistance of 0.001 , an annual discount rate of $3 \%$ and time frame of (a) 5 years, (b) 10 years, and (c) 15 years. DALYs = disability adjusted life years; ICERs $=$ incremental cost effectiveness ratio; SP $=$ sulfadoxine-pyrimethamine. ACT $=$ artemisinin-based combination therapy.

gued that a $50 \%$ threshold should be adopted as a basis for determining cost-effectiveness. ${ }^{20}$ Adoption of a lower certainty criterion would raise the level of the threshold boundary across all time frames (i.e., expand the cost-effective area of the economic evaluation planes shown in Figure 3). Nevertheless the $95 \%$ cut-off is useful since decision makers tend to be risk adverse in sanctioning policy changes, ${ }^{9}$ and given the financial implications of advocating a significantly more expensive drug, the greater the certainty of cost-effectiveness the more helpful is the analysis in informing policy decisions.

To interpret the results from this model, consideration must be made of the unregulated prescription of combination therapy drugs. If one or both of the component drugs is made available individually through the private or informal sectors, resistance to the combination therapy is likely to develop more rapidly. A similar argument may be made for drugs that act through similar mechanisms, such as artesunate and artemether, in which resistance to one drug will have negative effects on the efficacy of the other. However, the availability of drugs through the private sector will impact on the growth of resistance of all alternative first-line therapies, ACTs as well as currently used therapies such as SP. Therefore, private sector availability may be neutral in its impact on the relative growth of ACT and SP resistance. However, even if private sector availability impacts differentially more on the growth rate of resistance to ACT, it seems unlikely that the impact could be so great as to alter the decision for a policy switch under the majority of the settings represented by the parameter space in Figures 3 and 4.

The structure of the model is flexible in that it can be adapted to examine a range of alternative first-line treat- ments, and, through varying the input parameters, to analyze specific epidemiologic and economic scenarios. The framework may also be used to quantify the influence of key variables on the location of the threshold conditions. Three key variables that should be further examined as more empirical data become available are 1) the expected cost of the ACT, including not only drug price but other costs associated with its implementation, 2) the level of compliance to the ACTs, and 3 ) the initial level of drug resistance, as shown by the difference in threshold conditions in Figure 3 (initial ACT resistance set at 1 in 1,000) and Figure 4 (initial ACT resistance set at 1 in 100).

While the model performs well in avoiding the problem associated with a lack of basic knowledge on the key parameter of ACT growth of resistance, it has several limitations that may influence the predicted outcomes. First, the framework is based on a previous model that focused only on the population seeking care through formal inpatient/outpatient facilities. It does not consider the whole population at risk of malaria, nor accommodate the range of patient-seeking behaviors in, for example, the private sector. Second, although a logistic function is used to capture the temporal dynamics of resistance, there is no link between the growth rate of resistance and those factors dictating the evolution of resistance, such as drug pressure, compliance to drug regimens, drug decay rates, and parasite recombination rates. Also, the links between levels of treatment failure, patient compliance, and overall patterns of drug usage are also dynamic, which is not captured. Third, the effects of transmission intensity and other malaria interventions are not included; rather the model is restricted to the presentation of true malaria-positive

TABLE 3

Same analysis as shown in Table 2 over a time frame of (a) 5 years, (b) 10 years, and (c) 15 years, but assuming an ACT starting resistance of $0.01 *$

\begin{tabular}{|c|c|c|c|c|c|c|c|c|c|c|c|}
\hline $\begin{array}{l}\text { (a) } \\
\mathrm{R}_{\mathrm{SP}, 0}\end{array}$ & Costs incurred & DALYs averted & ICER & $\begin{array}{l}\text { (b) } \\
\mathrm{R}_{\mathrm{SP}, 0}\end{array}$ & Costs incurred & DALYs averted & ICER & $\begin{array}{l}\text { (c) } \\
\mathrm{R}_{\mathrm{SP}, 0}\end{array}$ & Costs incurred & DALYs averted & ICER \\
\hline 0.1 & $\$ 5.99$ & 0.02 & $\$ 370.85$ & 0.1 & $\$ 6.35$ & 0.03 & $\$ 199.21$ & 0.1 & $\$ 6.46$ & 0.03 & $\$ 185.84$ \\
\hline 0.2 & $\$ 5.35$ & 0.09 & $\$ 60.09$ & 0.2 & $\$ 5.86$ & 0.12 & $\$ 48.43$ & 0.2 & $\$ 5.97$ & 0.12 & $\$ 48.05$ \\
\hline 0.3 & $\$ 4.99$ & 0.16 & $\$ 32.16$ & 0.3 & $\$ 5.48$ & 0.19 & $\$ 28.63$ & 0.3 & $\$ 5.59$ & 0.19 & $\$ 28.70$ \\
\hline 0.4 & $\$ 4.68$ & 0.21 & $\$ 22.00$ & 0.4 & $\$ 5.15$ & 0.25 & $\$ 20.51$ & 0.4 & $\$ 5.26$ & 0.25 & $\$ 20.66$ \\
\hline 0.5 & $\$ 4.40$ & 0.26 & $\$ 16.65$ & 0.5 & $\$ 4.86$ & 0.30 & $\$ 15.98$ & 0.5 & $\$ 4.97$ & 0.31 & $\$ 16.16$ \\
\hline 0.6 & $\$ 4.14$ & 0.31 & $\$ 13.31$ & 0.6 & $\$ 4.60$ & 0.35 & $\$ 13.05$ & 0.6 & $\$ 4.71$ & 0.36 & $\$ 13.23$ \\
\hline 0.7 & $\$ 3.90$ & 0.35 & $\$ 11.00$ & 0.7 & $\$ 4.35$ & 0.40 & $\$ 10.98$ & 0.7 & $\$ 4.46$ & 0.40 & $\$ 11.15$ \\
\hline 0.8 & $\$ 3.68$ & 0.40 & $\$ 9.30$ & 0.8 & $\$ 4.13$ & 0.44 & $\$ 9.42$ & 0.8 & $\$ 4.24$ & 0.44 & $\$ 9.59$ \\
\hline 0.9 & $\$ 3.47$ & 0.43 & $\$ 7.98$ & 0.9 & $\$ 3.91$ & 0.48 & $\$ 8.20$ & 0.9 & $\$ 4.02$ & 0.48 & $\$ 8.37$ \\
\hline
\end{tabular}


individuals and does not accommodate changes in underlying rates of malaria in different sections of the population. Fourth, cost-effectiveness is only one criterion on which policy decisions are based. Importantly, cost-effectiveness estimates are not informative for issues of affordability. Since the exclusive use of a cost-effectiveness threshold theoretically can lead to a prescription for unlimited expansion of the health service, it will be necessary to account for affordability in further work.

While all four shortfalls of the approach should be addressed by future research, ideally through theoretical developments guided by empirically measured parameters, the model presented here provides a structured means of robustly quantifying the likely range of conditions under which switching from SP to an ACT is likely to be cost-effective. Crucially, given current limited production of ACTs, a considerable amount of forward planning and logistical support must be in place to ensure that ACTs are widely available before advocating a switch in policy.

Received August 21, 2003. Accepted for publication December 8, 2003.

Acknowledgments: We thank Andrew Briggs for facilitating the collaboration between the Health Economics Research Centre (University of Oxford) and the London School of Hygiene and Tropical Medicine and for his input to the modeling.

Financial support: This study was supported by the Institute of Medicine and the World Health Organization.

Authors' addresses: Paul G. Coleman, Disease Control and Vector Biology Unit, Department of Infectious and Tropical Diseases, London School of Hygiene and Tropical Medicine, Keppel Street, London WC1E 7HT, United Kingdom, Telephone: 44-207-927-2333, Fax: 44-207-580-9075. E-mail: Paul.Coleman@lshtm.ac.uk. Chantal Morel, Catherine Goodman, and Anne J. Mills, Health Economics and Financing Program, Department of Public Health and Policy, Health Policy Unit, London School of Hygiene and Tropical Medicine, Keppel Street, London WC1E 7HT, United Kingdom, E-mails: Chantal.Morel@lshtm.ac.uk, Catherine.Goodman@lshtm.ac.uk, and Anne.Mills@lshtm.ac.uk. Samuel Shillcutt, Health Economics Research Centre, University of Oxford, Old Road, Headington, Oxford OX3 7LF, United Kingdom and Department of Economics, School of Social Sciences, City University, Northampton Square, London EC1V 0HB, United Kingdom, E-mail: Samuel.Shillcutt@publichealth.oxford.ac.uk.

\section{REFERENCES}

1. Nosten F, van Vugt M, Price R, Luxemburger C, Thway KL, Brockman A, McGready R, ter Kuile F, Looareesuwan S, White NJ, 1999. Viewpoint: averting a malaria disaster. Lancet 353: 1965-1967.

2. Bloland PB, Kazembe PN, Oloo AJ, Himonga B, Barat LM, Ruebush TK, 1998. Chloroquine in Africa: critical assessment and recommendations for monitoring and evaluating chloroquine therapy efficacy in sub-Saharan Africa. Trop Med Int Health 3: 543-552.

3. Bloland PB, Ettling M, Meek S, 2000. Combination therapy for
African malaria: hype or hope? Bull World Health Organ 78: 1378-1388.

4. McIntosh HM, Olliaro P, 2002. Artemisinin derivatives for treating uncomplicated malaria. Cochrane Database Systematic Review.

5. White NJ, 1999. Delaying antimalarial drug resistance with combination chemotherapy. Parassitologia 41: 301-308.

6. Hastings IM, Watkins WM, White NJ, 2002. The evolution of drug-resistant malaria: the role of drug elimination half-life. Philos Trans R Soc Lond B Biol Sci 357: 505-519.

7. Kindermans JM, Pécoul B, Perez-Casas C, Den Boer M, Berman D, Cox I, 2002. Changing National Malaria Treatment Protocols in Africa: What Is the Cost and Who Will Pay? Médicins sans Frontières Campaign for Access to Essential Medicines. Background Paper for the Roll Back Malaria Partnership Meeting on Improving Access to Antimalarial Treatment. Geneva: World Health Organization. September 30 to October 2 .

8. Bloland PB, 2001. Drug Resistance in Malaria. Geneva: World Health Organization.

9. Goodman CA, Coleman PG, Mills A, 2001. Changing the first line drug for malaria treatment - cost-effectiveness with highly uncertain inter-temporal trade-offs. Health Econ 10: 731-749.

10. WHO/CTD, 1996. Assessment of Therapeutic Efficacy of Antimalarial Drugs for Uncomplicated Falciparum Malaria with Intense Transmission. Geneva: World Health Organization. WHO/MAL/96.1077

11. Goodman CA, Coleman PG, Mills A, 1999. Cost-effectiveness of malaria control in sub-Saharan Africa. Lancet 354: 378-385.

12. Murray CJL, Lopez AD, 1996. The Global Burden of Disease: A Comprehensive Assessment of Mortality and Disability from Diseases, Injuries, and Risk Factors in 1990 and Projected to 2020. Cambridge, MA: Harvard University Press.

13. Goodman CA, Coleman PG, Mills A, 2000. Economic Analysis of Malaria Control in Sub-Saharan Africa. Geneva: World Health Organization. Global Forum for Health Research.

14. Roper C, Pearce R, Bredenkamp B, Gumede J, Drakeley C, Mosha F, Chandramohan D, Sharp B, 2003. Antifolate antimalarial resistance in southeast Africa: a population-based analysis. Lancet 361: 1174-1181.

15. WHO, 1996. Investing in Health Research and Development: Report of the Ad Hoc Committee in Health Research Relating to Future Intervention Options. Geneva: World Health Organization. TDR/Gen/96.1.

16. Curtis CF, Otoo LN, 1986. A simple model of the build-up of resistance to mixtures of anti-malarial drugs. Trans $R$ Soc Trop Med Hyg 80: 889-892.

17. Hastings IM, D’Alessandro U, 2000. Modelling a predictable disaster: the rise and spread of drug-resistant malaria. Parasitol Today 16: 340-347.

18. Phillips M, Phillips-Howard PA, 1996. Economic implications of resistance to antimalarial drugs. Pharmacoeconomics 10: 225 238.

19. Sudre P, Breman JG, McFarland D, Koplan JP, 1992. Treatment of chloroquine-resistant malaria in African children: a costeffectiveness analysis. Int J Epidemiol 21: 146-154.

20. Claxton K, 1999. The irrelevance of inference: a decision-making approach to the stochastic evaluation of health care technologies. J Health Econ 18: 341-364.

21. Kindermans JM, 2002. ACTs: Availability and Prices. Geneva: World Health Organization. Presentation at Roll Back Malaria Partners Meeting, October 1. 